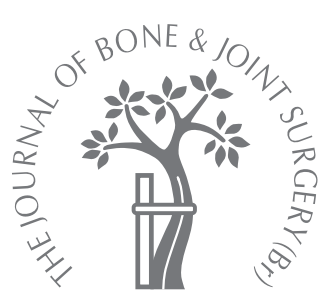

M. J. Shelly, J. S. Butler, M. Timlin, M. G. Walsh, A. R. Poynton, J. M. O’Byrne

From Mater Misericordiae University Hospital, Dublin, Ireland

M. J. Shelly, MRCSI, Lecturer in Trauma \& Orthopaedic Surgery

J. S. Butler, MB BCh, BAO, Orthopaedic Research Fellow

M. Timlin, MCh, MRCSI,

Specialist Registrar in Trauma

\& Orthopaedic Surgery

M. G. Walsh, FRCSI,

Consultant Orthopaedic

Surgeon

A. R. Poynton, MD, FRCSI(Tr

\& Orth), Consultan

Orthopaedic Surgeon

National Spinal Injuries Unit

Mater Misericordiae University

Hospital, Eccle Street, Dublin 7, Ireland.

I. J. O. O'Byrne, MCh, FRCSI, Abraham Colles Professor of

Trauma \& Orthopaedic Surgery RCSI Professorial Unit

Cappagh National Orthopaedic Hospital, Finglas, Dublin 11, Ireland.

Correspondence should be sent to Dr M. J. Shelly; e-mail: martinshelly@eircom.net

(C)2006 British Editorial Society of Bone and Joint Surgery doi:10.1302/0301-620X.88B6.

$17388 \$ 2.00$

$J$ Bone Joint Surg $[\mathrm{Br}]$

2006:88-B:771-5.

Received 4 November 2005

Accepted after revision

14 February 2006

\title{
Spinal injuries in Irish rugby
}

\author{
A TEN-YEAR REVIEW
}

This study assessed the frequency of acute injury to the spinal cord in Irish Rugby over a period of ten years, between 1995 and 2004. There were 12 such injuries; 11 were cervical and one was thoracic. Ten occurred in adults and two in schoolboys. All were males playing Rugby Union and the mean age at injury was 21.6 years (16 to 36 ). The most common mechanism of injury was hyperflexion of the cervical spine and the players injured most frequently were playing at full back, hooker or on the wing. Most injuries were sustained during the tackle phase of play. Six players felt their injury was preventable. Eight are permanently disabled as a result of their injury.

Injury is an inevitable consequence of participation in contact sports such as rugby and an acute spinal cord injury (ASCI) is one of the most devastating a player can sustain. The mortality and morbidity associated with these injuries have a major impact on the affected player and on society as a whole. Studies in New Zealand ${ }^{1}$ and South Africa ${ }^{2}$ have noted an increase in frequency of this type of injury in Rugby Union. The cervical spine is particularly vulnerable to injury because it is essentially a mobile column with a large weight, the head, on its upper end ${ }^{3}$ and, unlike the rest of the spine, it has greater mobility, smaller vertebral bodies, oblique articular facets and weaker muscle protection. ${ }^{4}$

Injury to the cervical spine can be caused by either extreme flexion, with or without rotation of the neck, or hyperextension. Hyperflexion injuries are more common and occur when a force is exerted through the vertex of the head and transmitted through the skull to the cervical vertebrae. The vertebrae are crushed together and the vertebral body and disc extrude posteriorly into the cervical canal. Hyperflexion can also cause dislocation. Forced flexion of the neck is often observed during collapse of the scrum while the injured player's own scrum or that of the opposition continue to push. ${ }^{4,5}$ During extreme extension of the neck, the spinal canal is narrowed and may lead to the cord being seriously damaged. If the force of impact is great enough, fracture of the posterior bony elements occurs as they impinge on one another. This type of damage is typically seen when front rows 'charge in' dur- ing the engagement of the scrum and the head of a player is not correctly aligned. ${ }^{4}$

This study assesses the frequency of ASCI's in Irish Rugby between 1995 and 2004.

\section{Patients and Methods}

Rugby is a popular sport in Ireland, with approximately 90000 players registered with the Irish Rugby Football Union (IRFU). This retrospective study describes ASCI in rugby players referred to the National Spinal Injuries Unit between January 1995 and December 2004. This is the only unit in the Republic of Ireland which specialises in ASCI and receives referrals from other trauma units across the Republic of Ireland, from where such injured patients are assessed, stabilised and transferred urgently.

Between January 1995 and December 2004, 12 rugby players with ASCI were admitted to the National Spinal Injuries Unit. We included in the study those who had been a participant in an official IRFU game and had a well-documented, objective neurological deficit consistent with ASCI at their initial assessment. There were a further ten patients with injuries to the vertebral column without spinal cord deficit identified during the study period, but these were excluded because they had been managed at non-specialist centres and their inclusion would have led to erroneous data as to incidence. In order to isolate an appropriate cohort of patients we accessed the database of the National Spinal Injuries Unit to identify all patients admitted between 1995 and 2004 as a result of a spinal cord injury incurred while 
Table I. The Frankel grading system of neurological disability ${ }^{7}$

\begin{tabular}{ll}
\hline Grade & Motor/sensory function \\
\hline A & Complete loss of motor and sensory function below the level of the cord lesion \\
B & Some sensation below the level of the lesion, but complete motor paralysis \\
C & Some motor power below the level of the lesion, but insufficient for practical use \\
D & Useful motor power below the level of the lesion \\
E & No neurological symptoms (abnormal reflexes may be present) \\
\hline
\end{tabular}

Table II. Details of the injured players

\begin{tabular}{clllll}
\hline Case & Age & Level of injury & Mechanism of injury & Phase of play & Treatment \\
\hline 1 & 27 & C4/5 & Hyperextension C-spine & Maul & Anterior decompression/fusion C4/5 \\
2 & 19 & C5/6 & Hyperflexion C-spine & Being tackled & Anterior decompression/fusion C5/6 \\
$3^{\dagger}$ & 21 & C5/6 & Hyperflexion C-spine & Being tackled & Anterior decompression/fusion C5/6 \\
4 & 18 & C5/6 & Hyperextension C-spine & Being tackled & Posterior decompression/fusion C5/6 \\
5 & 16 & C5/6 & Hyperflexion C-spine & Tackling opponent & Anterior decompression/fusion C4/6 \\
6 & 18 & C5/6 & Hyperflexion C-spine & Scrum (collapse) & Anterior decompression/fusion C5/6 \\
7 & 25 & C4/5 & Hyperflexion C-spine & Tackling opponent & Anterior decompression/fusion C4/5 \\
8 & 19 & C5/6 & Hyperextension C-spine & Scrum (engagement) & Anterior decompression/fusion C4/6 \\
$9^{\dagger}$ & 20 & C5/6 & Hyperflexion C-spine & Being tackled & Skeletal traction + halo brace \\
10 & 23 & C5/6 & Hyperflexion C-spine & Being tackled & Skeletal traction + halo brace \\
11 & 36 & T12/L1 & Hyperflexion T-spine & Tackling opponent & Posterior decompression/fusion T10 to L1 \\
12 & 17 & C4/5 & Hyperflexion C-spine & Ruck & Anterior decompression \\
\hline
\end{tabular}

* C-spine, cervical spine; T-spine, thoracic spine

† patient lost to follow-up

playing rugby. The medical records for these players were then reviewed and all relevant information was retrieved, including the age at the time of injury, length of hospital stay, the anatomical location and description of the injury, radiological findings and details of any operative intervention. A structured telephone interview was then held with each player to gain the following information; the position held on the field at time of injury and whether this was their regular position; whether the injury was sustained during a competitive match or practice; the mechanism of injury; the phase of play during which the injury occurred; the nature of the playing surface; the level of the game and the rugby code (Rugby Union/League); whether the player considered that the injury could have been prevented and if so, how. Information was also gathered regarding the post-operative rehabilitation, if any, which the player underwent. Following the advice of a previous study, ${ }^{6}$ we personally interviewed ten players and it was evident that they had an accurate and comprehensive recollection of the circumstances of their injury and subsequent management. Two further players were lost to follow-up.

The Frankel system ${ }^{7}$ was used to classify the outcome (Table I).

\section{Results}

During the study period, 12 ASCI occurred (Table II), with a mean frequency of 1.2 (1 to 2 ) such injuries per year. No significant change in frequency took place on a yearly basis. The 12 patients consisted of ten adults and two schoolboys under the age of 18 years at the time of injury. There were 11 injuries to the cervical spine and one to the thoracic. The mean age at injury was 21.6 years (16 to 36 ) and all the

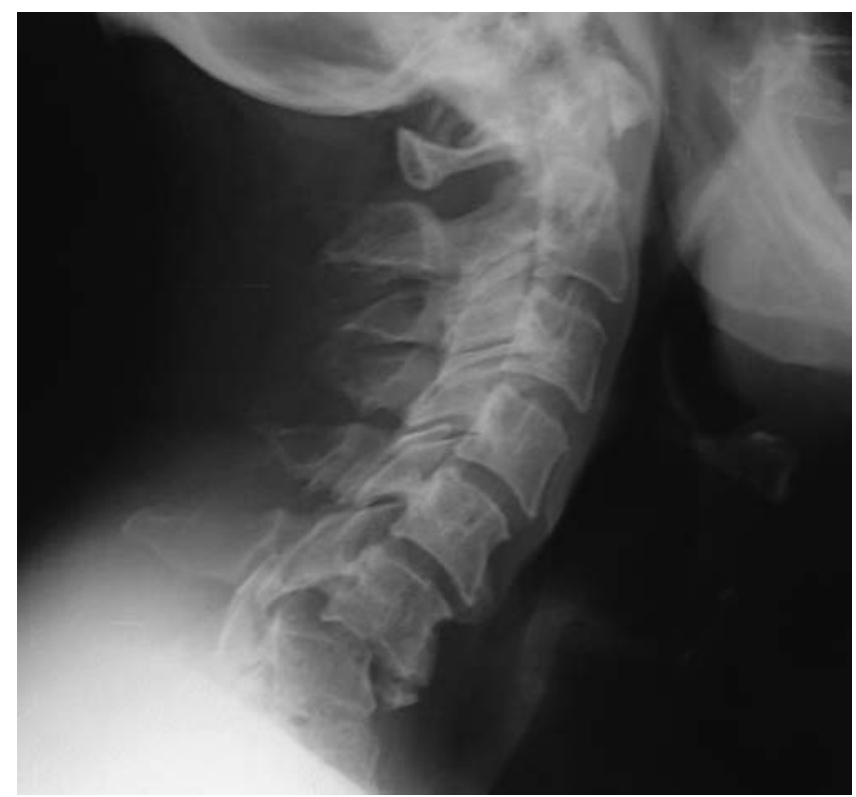

Fig. 1

Fracture dislocation at $\mathrm{C} 6 / 7$, secondary to a hyperflexion injury during a competitive rugby match.

patients were male. The mean length of stay in the National Spinal Injuries Unit was 15.1 days (2 to 45 ). The most common mechanism of injury was hyperflexion of the spine which occurred in nine patients (Fig. 1), and hyperextension occurred in three. Players with hyperflexion injuries 
Table III. The number of players injured at each level of play

\begin{tabular}{ll}
\hline Level of play $^{*}$ & Number of players injured \\
\hline AIL Division 1, First XV & 5 \\
AIL Division 1, Second XV & 2 \\
AIL Division 2, First XV & 2 \\
AIL Division 2, Second XV & 1 \\
Leinster Schools Senior Cup, First XV & 2 \\
\hline * AlL, All-Ireland League &
\end{tabular}

Table IV. Initial and final neurological status of each injured player

\begin{tabular}{clll}
\hline Case & Initial neurological status & $\begin{array}{l}\text { Final neurological } \\
\text { status }\end{array}$ & $\begin{array}{l}\text { Frankel } \\
\text { grade }^{7}\end{array}$ \\
\hline 1 & Complete C5 & Complete C5 & $\mathrm{A}$ \\
2 & Complete C5 & Complete C5 & $\mathrm{A}$ \\
$3^{*}$ & Complete C5 & Complete C5 & $\mathrm{A}$ \\
4 & Incomplete C6 & Normal & $\mathrm{E}$ \\
5 & Complete C5 & Complete C5 & $\mathrm{A}$ \\
6 & Complete C5 & Complete C5 & $\mathrm{A}$ \\
7 & Complete C5 & Complete C5 & $\mathrm{A}$ \\
8 & Incomplete C5 & Normal & $\mathrm{E}$ \\
$9^{*}$ & Incomplete C6 & Normal & $\mathrm{E}$ \\
10 & Incomplete C6 (Stinger syndrome) & Normal & $\mathrm{E}$ \\
11 & Complete T12 & Complete T12 & $\mathrm{A}$ \\
12 & Complete C5 & Complete C5 & $\mathrm{A}$ \\
\hline
\end{tabular}

* patient lost to follow-up

had a poorer neurological outcome than those who sustained hyperextension. Of the nine players in the hyperflexion group, seven remained permanently disabled, compared with one of three players with hyperextension injuries. All the players were injured while playing Rugby Union and twice as many injuries (8 of 12) occurred in those who played as backs compared with forwards. Those injured most commonly were playing at full back, hooker or on the wing. All were injured while playing in their regular positions during competitive matches, in either the AllIreland League or the Leinster Schools Senior Cup. The AllIreland is a semi-professional league with four divisions. The top division of the All-Ireland League is comparable to the Second XV of a Guinness Premiership club. The Leinster Schools Senior Cup is a fiercely competitive interschool competition for boys aged 16 to 18 years. The numbers of players injured and their level of play is indicated in Table III.

Of the 12 patients, eight sustained their injury during the tackle phase of play, with five players injured while being tackled by an opponent and three while initiating a tackle. All tackles were felt to be fair and legal, with no high, late or spear tackles reported. Players injured while tackling an opponent reported that their injury was contributable to poor technique, with all three players reporting a hyperflexion injury after striking the lower limbs of their opponents. Of those injured whilst being tackled, there were four hyperflexion injuries and one hyperextension. Two injuries occurred during the scrum, with one at scrum

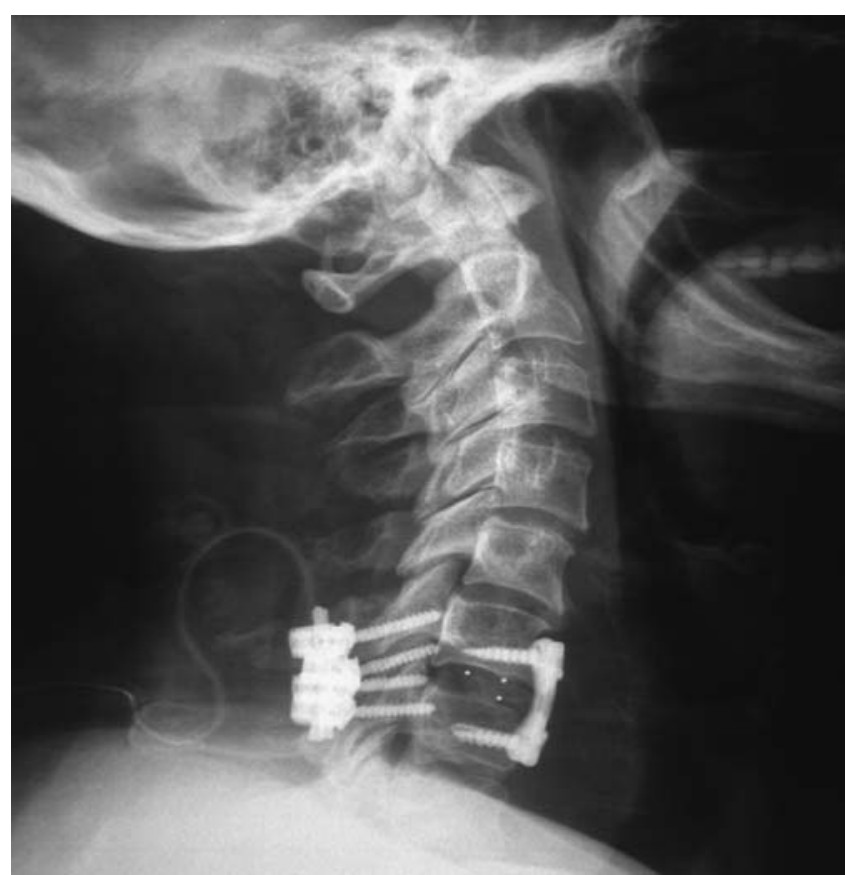

Fig. 2

Radiograph showing open reduction and internal fixation of the cervical spine dislocaton at $\mathrm{C} 6 / 7$.

engagement (hyperextension) and one following the collapse of the scrum (hyperflexion). Rucks and mauls are phases of play which occur after a tackle, when at least one player from each side is in close physical contact around the ball carrier. If the ball carrier is grounded, it is a ruck and if standing, a maul. There were two injuries which occurred during the ruck and maul phase of play, with one during a ruck (hyperflexion) and one during a maul (hyperextension).

Eleven of the players reported that the playing surface was adequate at the time of injury, but one stated that the playing surface was wet and uneven and contributed to his injury. There were six players who felt that their injuries could have been prevented if there had been stricter control by the referee, better first aid on the scene, improved coaching, especially in the technique of tackling and a better condition of the playing surface. All players interviewed stated that the immediate 'on-field' management of their injury was inadequate, with first responders having little or no training in the acute management of a player with a spinal injury. This finding is supported by an earlier study by McCoy et $\mathrm{al}^{5}$ which highlighted this issue and made the recommendation that medical and paramedical personnel involved in rugby should receive appropriate first-aid training. We support this recommendation and that by Horan, ${ }^{8}$ that first-aid training should be developed in conjunction with orthopaedic surgeons.

On initial assessment, eight players presented with complete neurological deficit (absence of motor function and 
sensation below the level of the cord lesion), while the remainder suffered incomplete neurological injuries with some preservation of motor function and sensation below the level of the lesion. There was one injury at T12 (Table IV).

A complete injury at $\mathrm{C} 5$ or above contributes to total disability, compared with an injury in which C6 function is preserved. Complete C5 lesions occurred in seven players. Ten players underwent open reduction and internal fixation of the spine at the level of injury (Fig. 2). Two were managed by cervical spine traction and immobilisation in a Halo brace (Jerome Medical, Moorestown, New Jersey).

Of the 12 players injured, 11 had a period of neurorehabilitation, whilst one did not require rehabilitation because his neurological deficit resolved completely during his stay as an in-patient in the Unit. In-patient neurorehabilitation was given to nine players, with the mean length of stay being 9.2 months (5 to 14), whilst the remaining two were managed on an out-patient basis. A total of seven players remain completely dependent on carers to carry out their activities of daily living. One remains paraplegic but is independent in activities of daily living because he has normal function of the upper limbs. Full neurological recovery occurred in four players who are currently independent in activities of daily living. At long-term follow-up (mean 5.9 years; 1 to 10 ) eight were wheelchair-dependent (Frankel grade A) and four had regained normal neurological function (Frankel grade E) (Table IV). ${ }^{7}$ Only one player, who suffered an anterior subluxation of C5 on C6 with mild oedema of the cervical cord returned to playing rugby.

\section{Discussion}

Although injuries are inevitable in contact sports, all those involved have a duty of care to minimise them. A recent study ${ }^{9}$ has suggested that the best way of achieving this in rugby is to obtain data prospectively for each injury, using a registry which works in co-operation with the safety committees of the Rugby Unions. A central reporting body for serious spinal injuries due to rugby has been advocated since the late 1970 s. ${ }^{10} \mathrm{~A}$ registry of serious injury is central to the administration of any sport where there is an established risk of subsequent disability or even death for the participants. On-going surveillance of trends and mechanisms of injury can indicate necessary law changes. ${ }^{9}$ The evidence supporting such a registry is compelling. In 1975, a National Football Head and Neck Registry was established in the USA for American Football. ${ }^{11}$ It was demonstrated, using this registry, that the protective helmet worn by players was being used to intentionally strike an opponent; players were using their helmeted heads as a battering ram deliberately striking opponents with their head in an attempt to take them down. This led to radical law changes for the 1977 season. Subsequently, the incidence of ASCI at all levels of participation fell from 34 cases in 1976 to 18 in $1977 .{ }^{11}$ A registry is the starting point for research and, most importantly, for the safety education of coaches, trainers, referees and players. ${ }^{9}$

In the UK in 1980, the Rugby Football Union (RFU) issued a definitive statement on injuries in schools following work by the Medical Officers of Schools Associations. ${ }^{12}$ Subsequently, the RFU set up a working party that initiated changes for school rugby relating to scrums, rucks and mauls. These changes became effective in the 1985/86 season on an international basis. ${ }^{13}$ Since 1985 , there has been a $67 \%$ reduction in the number of spinal injuries due to scrum-engagement recorded in Australia. ${ }^{9}$ A dramatic reduction in the overall number of injuries after appropriate changes in the laws was also noted in a large study by Silver and Stewart. ${ }^{14}$

Our study identifies a number of risk factors for spinal cord injuries in rugby players.

Match play. The most obvious risk factor was match play, with all ASCI occurring during competitive matches. A similar percentage was reported in Australian ${ }^{9}$ and Argentinian studies. ${ }^{4}$ In contrast, Burry and Gowland ${ }^{15}$ observed that one third of injuries occurred during training or social games. This finding is especially significant, since considerably more time is spent in practice than in match play. It appears that the competitive nature and aggression of the players is unleashed in match play and is an important contributary factor.

Age. The majority of injuries in this study were sustained by adults. This is significant in that in most rugby-playing countries, more schoolboys than adults play the game. In Ireland, there are approximately 73000 schoolboys registered with the IRFU, compared with 17000 adults (unpublished data). Early reports of spinal injuries suggested that schoolboys were at greater risk of sustaining injuries than players at senior level. ${ }^{5,15,16}$ Large studies from South Africa, ${ }^{17}$ Australia, ${ }^{9}$ New Zealand ${ }^{18}$ and Argentina ${ }^{4}$ have contradicted this finding, with adult injuries predominating.

Level of play. The risk of injury was greater at the higher levels of play. Seven players were injured at All-Ireland League Division 1, First or Second XV level. There were only two schoolboys injured and they were both playing senior First XV rugby. Because there are relatively few players of the total rugby-playing population participating at a high level, our findings suggest that a player with optimum skill and physical fitness carries a slightly higher risk of injury. This may be explained by their more aggressive approach to the game and a more dangerous style of play. ${ }^{17}$ Phase of play. There are four different phases of play that contribute to the majority of rugby injuries. In this study, tackling accounted for the majority of ASCIs ( 8 of 12 ), with the remaining injuries occurring in the scrum ( 2 of 12$)$ and ruck and maul (2 of 12). Interestingly, there are national differences in the proportion of injuries occurring in the different phases of play. In South Africa ${ }^{17}$ and Ireland there are fewer injuries in the scrum and more in the tackle, whereas in Argentina ${ }^{4}$ and Australia, ${ }^{9}$ scrums account for 
the majority of injuries. The explanations for these geographical differences are not clear, but this discrepancy does indicate that different preventive measures need to be emphasised in different countries. ${ }^{17}$

Player position. Backs suffered the majority of injuries ( 9 of 12). They were most commonly injured in the tackle, whereas forwards ( 3 of 12 ) were more prone to injury while scrummaging. Ruck and maul injuries were more common in backs in comparison with several large studies ${ }^{4,9,15,17}$ which found that forwards are more often injured in the ruck and maul. The full back was the most commonly injured in this study, but worldwide ${ }^{4,15,17,18}$ the hooker is most at risk. The reasons for these differences are not clear, but may be accounted for by the differing styles of play between nations. Irish rugby is an open style of play, with greater emphasis on the backs running with the ball and tackling, whereas in Argentina, the scrum is the focus of play and hence, forwards are placed at greater risk of injury.

Once a neurological deficit is established in a patient with an ASCI, the prognosis is very poor, as recovery is usually limited to the proximal muscles of the upper limbs. In this study there were only four cases of complete neurological recovery.

A registry of serious injuries is the starting point for research into ASCI and can identify worrying trends in mechanisms of injury, leading to necessary changes in the law. To date, such a registry does not exist in the Republic of Ireland.

No benefits in any form have been received or will be received from a commercial party related directly or indirectly to the subject of this article.

\section{References}

1. Armour KS, Clatworthy BJ, Bean AR, Wells JE, Clarke AM. Spinal injuries in New Zealand rugby and rugby league: a twenty year survey. N Z Med J 1997;110:462-5.

2. Scher AT. Rugby injuries to the cervical spine and spinal cord: a 10-year review. Clin Sports Med 1998;17:195-206.

3. Tencer AF. Biomechanics of spinal trauma: mechanisms, tissue tolerance and implant performance. In: Cotler JM, Simpson JM, An S, Silveri CP, eds. Surgery of spinal trauma. Philadelphia: Lippincott, Williams \& Wilkins, 2000:61-112.

4. Secin FP, Poggi EJ, Luzuriaga F, Laffaye HA. Disabling injuries of the cervical spine in Argentine rugby over the last 20 years. Br J Sports Med 1999;33:33-6.

5. McCoy GF, Piggot J, Macafee AL, Adair IV. Injuries of the cervical spine in schoolboy rugby football. J Bone Joint Surg [Br] 1984;66-B:500-3.

6. Taylor TK, Coolican MR. Spinal-cord injuries in Australian footballers, 1960-1985. Med J Aust 1987;147:112-18.

7. Frankel HL, Hancock DO, Hyslop G, et al. The value of postural reduction in the initial management of closed injuries of the spine with paraplegia and tetraplegia: I. Paraplegia 1969;7:179-92.

8. Horan FT. Injuries to the cervical spine in schoolboys playing rugby football. J Bone Joint Surg [Br] 1984;66-B:470-1.

9. Spinecare Foundation, The Australian Spinal Cord Injury Units. Spinal cord injuries in Australian footballers. ANZ J Surg 2003;73:493-9.

10. Hoskins TW. Rugby injuries to the cervical cord. Br Med J 1978;2:1783.

11. Torg JS, Vegso JJ, Sennett B, Das M. The National Football Head and Neck Injury Registry: 14-year report on cervical quadriplegia, 1971 through 1984. JAMA 1985; 254:3439-43.

12. Rugby Football Union. Statement on rugby injuries in schools. Br J Sports Med 1980;14:234-5.

13. Silver JR, Gill S. Injuries of the spine sustained during rugby. Sports Med 1988;5 328-34.

14. Silver JR, Stewart D. The prevention of spinal injuries in rugby football. Paraplegia 1994;32:442-53.

15. Burry HC, Gowland H. Cervical injury in rugby football: a New Zealand survey. Br J Sports Med 1981;15:56-9.

16. Williams JP, McKibbin B. Cervical spine injuries in Rugby Union football. Br Med J 1978;2:1747.

17. Kew T, Noakes TD, Kettles AN, et al. A retrospective study of spinal cord injuries in Cape Province rugby players, 1963-1989: incidence, mechanisms and prevention. S Afr Med J 1991;80:127-33.

18. Quarrie KL, Cantu RC, Chalmers DJ. Rugby union injuries to the cervical spine and spinal cord. Sports Med 2002:32:633-53. 